\title{
A Comparative Study of Propranolol Release by In Vitro Dissolution Profiles in Pharmaceutical Formulations
}

\author{
Adenilson P. Conceição ${ }^{1}$, Ramon R. Sá ${ }^{1}$, Vagner C. da Silva ${ }^{1}$, Matheus da S. Ferreira ${ }^{2}$, Edith C. L. \\ Cazedey ${ }^{3}$, Hemerson I. F. Magalhães ${ }^{4}$, and Aníbal de F. Santos Júnior 1,2* \\ ${ }^{1}$ Department of Life Sciences, Universidade do Estado da Bahia, 41195-001, Salvador, Bahia, Brazil \\ ${ }^{2}$ Department of Exacts and Earth Sciences, Universidade do Estado da Bahia, Salvador, Bahia, Brazil \\ ${ }^{3}$ College of Pharmacy, Universidade Federal da Bahia, Campus Ondina, Salvador, Bahia, Brazil \\ ${ }^{4}$ Departament of Pharmaceutical Sciences, Universidade Federal da Paraíba (UFPB),Campus Universitário, João Pessoa, Paraíba, Brazil
}

e-mail:afjunior@uneb.br

\begin{abstract}
Propranolol is a $\beta$-blocker used to modify or restore normal heart rhythm in cardiovascular diseases. The aim of this study was to compare the dissolution profiles of $40-\mathrm{mg}$ tablets of propranolol available as a reference, generic, and similar drug product, sold commercially in Bahia, Brazil, using a sensitive and rapid ultraviolet spectrophotometric method. The dissolution test was used to obtain and compare dissolution profiles and establish similarities of pharmaceutical formulations in compliance with the Brazilian and United States Pharmacopoeias (USP type 1 apparatus at 100 rpm with $1000 \mathrm{~mL} 0.1 \mathrm{~mol} / \mathrm{L} \mathrm{HCl}$ at $37.0 \pm 0.5^{\circ} \mathrm{C}$ for $1 \mathrm{~h}$ ). The similar and generic products showed rapid drug release $(>75 \%$ after $1 \mathrm{~min}$ of dissolution). The reference product showed a controlled drug release profile (> 75\% after $15 \mathrm{~min})$. In presence of sodium lauryl ether sulfate (SLES) $1 \%(\mathrm{v} / \mathrm{v})$ with propranolol, drug release profiles were slower, likely by chemical interactions between SLES and propranolol. Drug release profiles were satisfactory for all products, because at least $75 \%$ of propranolol was dissolved in the medium within 30 minutes.
\end{abstract}

KEYWORDS: Propranolol, dissolution, in vitro dissolution profiles, quality control

\section{INTRODUCTION}

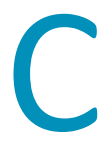

ardiovascular diseases (essential arterial hypertension, ischemic heart disease, cardiac arrhythmias, and others) are among the biggest cause of death in the world, being prevented or treated by several drugs, including $\beta$-blockers, used to modify or restore normal heart rhythm (1). Among the main drugs in this group, propranolol, designated chemically as (RS)1-(isopropylamino)-3-(naphthalen-1-yloxy)propan-2-ol (Fig. 1), a non-selective $\beta$-blocker agent, is observed, decreasing frequency and myocardial contractility during periods of intense sympathetic activity, resulting in decreased cardiac output (2).

The mechanism of the antihypertensive effect of propranolol has not been established. Factors that may contribute to the antihypertensive action include: (1) decreased cardiac output, (2) inhibition of renin release by the kidneys, and (3) diminution of tonic sympathetic nerve outflow from vasomotor centers in the brain (3).<smiles>CC(C)NCC(O)COc1cccc2ccccc12</smiles>

Figure 1. Molecular structure of propranolol.

Propranolol is a lipid-soluble compound and its dosage form as tablet is completely absorbed by the oral route (4). The bioavailability of propranolol depends on the degree of liver metabolism. Although the drug is some 90\%-95\% bound to plasma, hepatic removal is so rapid that both bound and free forms are extracted, and the drug shows a short plasma half-life, approximately 2-6 hours (5-7). 
Used as a hydrochloride, propranolol is available in three manufacturing categories in Brazil: reference, generic, and similar drugs (8). It is marketed in Brazil in the form of tablets $(10,40$, and $80 \mathrm{mg}$ ), capsules ( 80 and $160 \mathrm{mg})$, powder $(40 \mathrm{mg})$, and solution for injection (1 $\mathrm{mg} / \mathrm{mL})$. "Similar" drug products contains the same active ingredient and has the same concentration, pharmaceutical form, route of administration, posology, and therapeutic indication, and is equivalent to the medicine registered in the federal agency responsible for sanitary surveillance, and may differ only in characteristics related to the size and shape of the product, shelf-life, packaging, labeling, excipients, and vehicle, and similar drugs must always be identified by trade name or brand (9). Propranolol is soluble in water and permeable to the cell membrane. It is classified as a class I drug according to the Biopharmaceutical Classification System (BCS) and can be assessed for bioequivalence by using only the dissolution test (10-12). In vitro dissolution testing is an important tool used for development, control, and approval of generic dosage forms. It can also be used to predict the in vivo performance of certain products (13). Drug dissolution (or release) testing is used to assess release profiles of drugs in pharmaceutical products (14). One of the required pharmaceutical equivalence tests is the comparison of similar and generic drug release profiles to that of a reference drug. Drug dissolution profiles may be distinct due to differences in formulations and manufacturing processes, but the differences must not compromise the bioequivalence of the product (15).

Several pharmacopoeias, such as Brazilian and United States, recommend the use of UV spectrophotometry for the quantitative analysis of the drugs in dissolution test samples. As a class I drug, there are few studies of propranolol's dissolution kinetics (16-20); however, the presence of excipients and polymorphisms may alter the release of this drug (21). In the present study, we obtained in vitro dissolution profiles using a UV spectrophotometric method to evaluate the release of tablets containing 40 $\mathrm{mg}$ of propranolol (reference, generic and similar drugs).

\section{MATERIALS AND METHODS}

\section{Chemicals, Reagents, and Samples}

All reagents were of analytical grade. Doubly distilled water was obtained from a Q341 Quimis distiller (São Paulo, SP, Brazil) and used throughout the experiments. Hydrochloric acid $(\mathrm{HCl})$ was purchased from Quimex (Merck, São Paulo, SP, Brazil) and used as the dissolution medium for the dissolution tests. Sodium lauryl ether sulfate was purchased from Usiquimica (São Paulo, SP, Brazil) and used for additional tests. Propranolol reference standard was purchased from Sigma-Aldrich (São Paulo, $\mathrm{SP}$, Brazil).

Two lots of each type of propranolol tablets (reference, generic, and similar products) containing $40 \mathrm{mg}$ were used. The medicines for disintegration and dissolution tests and for profile comparison were purchased from three drug stores in Salvador, Bahia, Brazil. The samples were designated as:

Product R1 (reference product): labeled to contain 40 $\mathrm{mg}$ of the drug and the following excipients: magnesium stearate, gelatine, and lactose monohydrate.

Product G1 (generic product): labeled to contain $40 \mathrm{mg}$ of the drug and the following excipients: maize starch, microcrystalline cellulose, croscarmellose sodium, silicon dioxide, and magnesium stearate.

Product S1 (similar product): labeled to contain $40 \mathrm{mg}$ of the drug and the following excipients: sodium starch glycolate, microcrystalline cellulose, silicon dioxide and magnesium stearate.

The propranolol tablets were subjected to weight variation, disintegration, and dissolution tests following the Brazilian and United States Pharmacopoeias general methods applied to drugs $(22,23)$.

\section{Equipment}

The analysis of the weight variation was obtained on an electronic balance (Mark, M164-Al, Piracicaba, SP, Brazil). The friability tester was an Ethik Model HX 300-2 (Vargem Grande Paulista, SP, Brazil). The disintegration analyses were carried out on a Nova Ética system Model 301/AC 01 (Vargem Grande Paulista). The dissolution analysis was carried out on a multi-bath $(n=6)$ dissolution test apparatus: Ethik Model 299 (Vargem Grande Paulista) in accordance with the Brazilian Pharmacopoeia and United States Pharmacopoeia general methods. All spectrophotometric measurements were carried out using a Shimadzu model 1240 (Kyoto, Japan) UV-Vis spectrophotometer (190-1100 nm) equipped with a diode array detector. The absorbances of sample solutions were read in 1-cm quartz cells. The detector was set at $289 \mathrm{~nm}$.

\section{Calibration Standards}

A stock standard solution of propranolol $(500 \mu \mathrm{g} / \mathrm{mL})$ was prepared. Calibration standards with concentrations ranging from 5.0 to $40.0 \mu \mathrm{g} / \mathrm{mL}$ were prepared daily from the stock standard solution by appropriate dilution and analyzed in triplicate by UV spectrophotometry at $289 \mathrm{~nm}$. 


\section{Weight Variation, Friability and Disintegration Tests}

For each brand, 20 tablets were randomly selected and weighed individually in the analytical balance. The average of weights was determined and the percentage deviations from mean values were calculated. The percentage weight variation for each tablet was estimated according to the following formula, where AW is average weight and IW is individual weight: (AW - IW) / IW $\times 100$. The Brazilian and United States Pharmacopoeias establish a maximum variation of $\pm 7.5 \%$, and no more than two units outside the specified limits may be tolerated in relation to the average weight, but none may be above or below twice the indicated percentages $(22,23)$.

For the friability test, 20 tablets were randomly selected, weighed and placed into the Friability Tester at 100 rpm for 4 minutes $(25 \mathrm{rpm})$. The tablets were weighed again, and the differences in weight were calculated as the percentage of friability. The same was done for all selected brands. The difference between the initial weight and the final weight represents friability, that is, a measure of the percentage of powder lost. In accordance with Brazilian and United States Pharmacopeias, no tablet may be present at the end of the test, broken, chipped, cracked or split. Tablets with loss equal to or less than $1.5 \%$ of their weight or the percentage set forth in the monograph are acceptable.

The disintegration test checks if tablets disintegrate within the specified time limit, when six units of the batch are subjected to the action of specific apparatus under described experimental conditions. In the disintegration test apparatus, six units of each sample (tablets) of each brand were used under the following conditions: distilled water as disintegration medium at $37 \pm 1{ }^{\circ} \mathrm{C}$ and time of 30 minutes.

\section{Kinect Dissolution Studies}

Dissolution studies of 40-mg propranolol tablets were conducted using USP Apparatus 1 (basket) with six replicates at $37 \pm 0.5{ }^{\circ} \mathrm{C}$ and $100 \mathrm{rpm}$, and $0.1 \mathrm{~mol} / \mathrm{L}$ $\mathrm{HCl}$ was the dissolution medium $(1000 \mathrm{~mL})$. In all experiments, aliquots of $10 \mathrm{~mL}$ were withdrawn at predetermined time intervals $(1,3,5,10,15,20,25,30$, 45 , and $60 \mathrm{~min}$ ) and replaced with an equal volume of fresh medium to maintain a constant total volume in each vessel. Following filtration of dissolution samples using $0.45-\mu \mathrm{m}$ membrane filters, the concentrations of propranolol were determined by the proposed UV spectrophotometric method. The absorbances were converted to concentrations obtained from the equation on the standard curve. The calculations were performed considering the amount of drug removed in each aliquot. The results were expressed as percentages as a function of time. Also, the influence of sodium lauryl ether sulfate $1 \%(\mathrm{v} / \mathrm{v})$, a tensor agent commonly used in formulations, on the release of propranolol was investigated.

\section{Dissolution Efficiency}

Dissolution efficiency (DE) was used to evaluate the product dissolution performance under test conditions. This parameter was obtained from the area under the drug dissolution curve up to 60 minutes $\left(A \cup C_{0-t}\right)$, in relation to $100 \%$ of the product label value $\left(A \cup C_{T R}\right)$ (24-26). DE was expressed as a percentage and can be set by the following equation: $A \cup C_{0-t} / A U C_{T R} \times 100$, where $t$ is time ( $\mathrm{min}$ ) and TR is the product label value.

DE values were statistically analyzed using the Student's t-test with a significance level of $p \leq 0.05$. Factors $f 1$ and $f 2$ were not calculated because propranolol is a drug class I, according to the criteria in the literature (26). The DE results of the tested products were subjected to analysis of variance (ANOVA) using the Statistical Package for the Social Sciences (SPSS) software (version 22.0, IBM).

\section{Validation of Analytical Method}

The dissolution test was validated to demonstrate suitability $(25,27)$. Thus, analysis of linearity, precision (repeatability and intermediate precision), and accuracy were performed. Limit of detection (LOD) and quantification (LOQ) were also obtained for the proposed UV method. Possible interferences were evaluated by testing the components of the formulations and comparing to a placebo.

\section{RESULTS AND DISCUSSION}

\section{Validation of Analytical Method}

UV spectrophotometry has widespread usage in drug analysis because of its capability for rapid analysis with good repeatability (26). The samples obtained from dissolution studies were analyzed at $289 \mathrm{~nm}$. There was no interference from matrix components. The method was validated to demonstrate precision and accuracy. Linearity of propranolol's standard calibration curve was obtained with a regression equation $(y=0.0187 x$ $+0.0052)$ and a correlation coefficient $(r)$ greater than 0.99 in the concentration range studied $(5.0-40.0 \mu \mathrm{g} /$ $\mathrm{mL}$ ), which was used to calculate the amount of the drug dissolved in each sample.

The calculations of precision (repeatability and intermediate precision) and accuracy of the analytical method are shown in Table 1 . The results of LOD and LOQ were 0.093 and $0.27 \mu \mathrm{g} / \mathrm{mL}$, respectively. These results 
indicate reliability of the analysis, because the quantified values of propranolol dissolved in dissolution medium were above the quantification limit for all time points measured.

Table 1. Evaluation of Precision (Repeatability and Intermediate Precision) and Accuracy

\begin{tabular}{|c|c|c|}
\hline $\begin{array}{c}\text { Theoretical } \\
\text { Concentration } \\
(\mathbf{m g} / \mathrm{mL})\end{array}$ & CV (\%) & \multirow{2}{*}{$\begin{array}{c}\text { Accuracy } \\
(\%)\end{array}$} \\
\cline { 2 - 2 } & Repeatability; Intermediate & \\
\hline $\mathbf{5 . 0}$ & $0.152 ; 1.75$ & 98.3 \\
\hline $\mathbf{2 0 . 0}$ & $0.044 ; 0.91$ & 99.1 \\
\hline $\mathbf{4 0 . 0}$ & $0.089 ; 1.45$ & 98.7 \\
\hline
\end{tabular}

CV: coefficient of variation.

Propranolol concentration measurement accuracy was determined by average recovery (98.3\%-99.1\%). The precision of the UV spectrophotometric method was evaluated using values recorded on the same day (intraday) and alternate day (interday) in dissolution test standardized conditions. The relative standard deviation (RSD) values were less than $5 \%$, considering the UV method satisfactory.

\section{Average Weight, Friability, and Disintegration Tests}

Weight variation evaluation is applied to solid pharmaceutical forms (tablets) and allows for verification if tablets of the same batch have uniform weight. The objective of the weight variation test is to ensure good manufacturing practices. During tablet production, powder mixing is an important step, as lack of homogeneity of active ingredient and excipients may compromise product quality and safety, and variations in the contents may lead to harmful effects. Therefore, this test provides information on homogeneity, but does not provide information about the uniformity of drug content in each tablet (23).

The results showed that drugs reference and generic drugs have satisfactory weight variation values according to the Brazilian Pharmacopoeia (for capsules weighing up to $250 \mathrm{mg}$, the allowable variation range is $\pm 7.5 \%$ ). The analyzed samples had a weight variation between 179 and $216 \mathrm{mg}$, with a variation of $\pm 5.81 \%$. The similar drug product had variations of weight of $9.90 \%$, disagreeing with the Brazilian and United States Pharmacopoeias.

The results demonstrated that tablets have adequate friability. The reference drug showed loss of powder ranging from $0.05 \%$ to $0.31 \%$. The generic drug did not lose powder during the test. The similar drug product showed loss of powder less than $0.2 \%$. The test results of friability demonstrate that all three drug products comply with the Brazilian and United States Pharmacopoeias.
The disintegration test is used to check if tablets disintegrate within the specified time limit when six units of the batch are subjected to the action of the specific apparatus under described experimental conditions (23). Failure to disintegrate the tablets at the specified time can cause them to be eliminated intact or fragmented, not being absorbed by the body and therefore not producing the expected therapeutic effect, affecting the therapy. All formulations met the official compendium requirements for tablets (disintegration time of 30 minutes). Disintegration times are showed in the Table 2. Differences in disintegration times were noted between the reference drug and the generic and similar drugs. These differences are due to the presence of different excipients in the formulations. Generic and similar products contain a greater amount of excipients with disintegrating functions compared to those in this reference drug.

Table 2. Results of Disintegration Tests of Tablets Containing Propranolol $40 \mathrm{mg}$

\begin{tabular}{|c|c|}
\hline Product & Time \\
\hline Reference & 5 min $14 \mathrm{~s}$ \\
\hline Generic & $1 \mathrm{~min} 25 \mathrm{~s}$ \\
\hline Similar & $1 \mathrm{~min}$ \\
\hline
\end{tabular}

\section{Dissolution Test, Dissolution Profiles, and Dissolution Efficiency}

The Brazilian and United States Pharmacopoeias recommend that not less than $75 \%$ of the propranolol label amount $(40 \mathrm{mg})$ must dissolve within $30 \mathrm{~min}$. Several factors may affect rate of disintegration and dissolution of drug, such as the nature of the excipients, friability, compression force, hardness, polymorphisms, crystalline structure of drug, and isomers (28). All products were analyzed according to the official compendium recommendations. The reference, generic, and similar drug products had variations in the release of propranolol at the time points studied. Figure 2 gives the levels of propranolol in the dissolution media at $30 \mathrm{~min}$. In this time, all products released more than $75 \%$ of the propranolol label amount. Drug dissolution profiles are increasingly used to evaluate drug release characteristics of pharmaceutical products, formulation development, and final products for batch quality control and establishing similarity between test formulations and reference products (29). The results showed that the drugs are in accordance with the pharmacopoeial specification, since they released more than $75 \%$ after 30 minutes of test. 


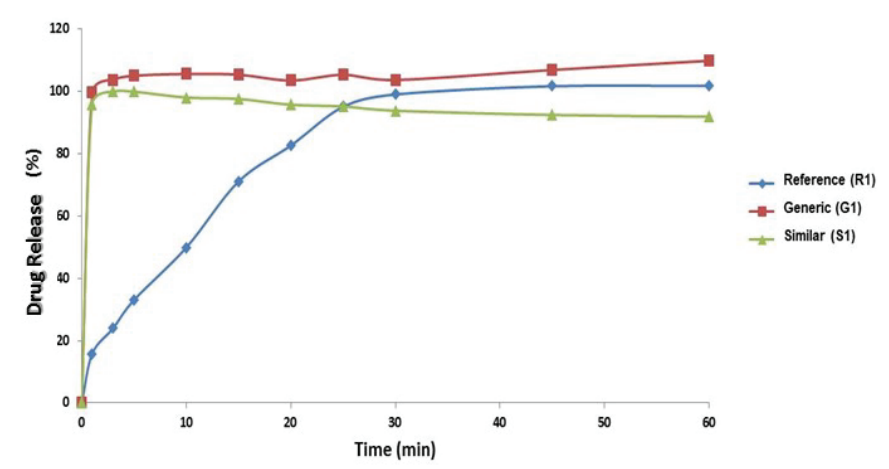

Figure 2. Comparative dissolution profiles of propranolol $(40 \mathrm{mg})$ tablets of reference, generic, and similar products. (USP type 1 apparatus at $100 \mathrm{rpm}$ with $1000 \mathrm{~mL} \mathrm{HCl} 0.1 \mathrm{~mol} / \mathrm{L}$ at $37.0 \pm 0.5^{\circ} \mathrm{C}$ for $1 \mathrm{~h}$.)

When comparing the dissolution profiles of the products, there is similarity between the generic and similar drugs. Within the first minute of testing, more than $90 \%$ of the drug was released from both formulations. For all times studied, the drug dissolution profiles of generic and similar drugs practically overlapped, indicating similarities in their dissolution profiles until the end of the test. One hypothesis for this is the presence of excipients with disintegrating functions in the generic and similar drug, which confer a faster disintegration time compared to the reference drug, which does not contain an excipient with a disintegrating function. Simultaneous assessment of the chemical and physical characteristics of the excipients present in the analyzed product is critical to justify possible variations in tablet mass as well as in disintegration and dissolution results $(30,31)$. Because the drugs presented rapid dissolution profiles ( $>75 \%$ in $15 \mathrm{~min}$ ), the $f 1$ and $f 2$ factors were not considered.

In vitro dissolution tests are important for predicting information about the bioavailability of a drug, as they link the dissolution profile (in vitro) of drug release with bioavailability (in vivo). These tests show pharmaceutical equivalence (same biopharmaceutical specifications of the test and reference products), which is relevant given the possibility of interchangeability between drug products (32). This is extremely important, because many patients search the lowest cost medicine to replace not only reference drugs with generic or similar products, but also generic drugs for other generic and similar products (33). In this study, the results showed that the reference, generic, and similar drug products analyzed are equivalent.

Furthermore, propranolol release from tablets was also assessed through DE by comparison of dissolution profiles. For appropriate comparison of DE values, the experimental setup was based on the same apparatus and medium. This parameter is related to the actual amount of drug dissolved in the solution and thus can give a better prognosis of the results in vivo (34). The reference, generic, and similar drug products showed DE values of $82.16,99.17$, and $99.11 \%(p<0.05)$, respectively. The efficiency of dissolution is not a comparative parameter of dissolution kinetics, but it is a parameter which characterizes drug release.

Surface active or tensioactive agents are a group of compounds with specific chemical composition of their molecules (one part soluble in polar medium [hydrophilic] and one part soluble in nonpolar medium [hydrophobic]). The main classification of surfactants is based on charge of hydrophilic parts of their molecules: cationic, anionic, and nonionic compounds (35). To assess the influence of tensioactive agents, the dissolution tests were conducted in sodium lauryl ether sulfate (SLES) $1 \%(\mathrm{v} / \mathrm{v})$, an anionic surfactant, which, according to the hydrophilic lipophilic balance (HLB) classification, is considered hydrophilic due to the its high HLB value (estimated at 40) (36). The use of surfactants in dissolution media is one of the main ways to increase the solubility of insoluble or slightly water soluble drugs $(11,36)$. Theoretically, propranolol, being a class I drug by BCS, would not require surfactants incorporated into formulations containing propranolol; however, in the formulations analyzed, some disintegrating agents were present on the labels (starch, microcrystalline cellulose, sodium starch glycollate, and croscarmellose sodium). In this context, we chose SLES due to low cost and availability in the laboratory. Figure 3 shows dissolution profiles of propranolol in presence of SLES.

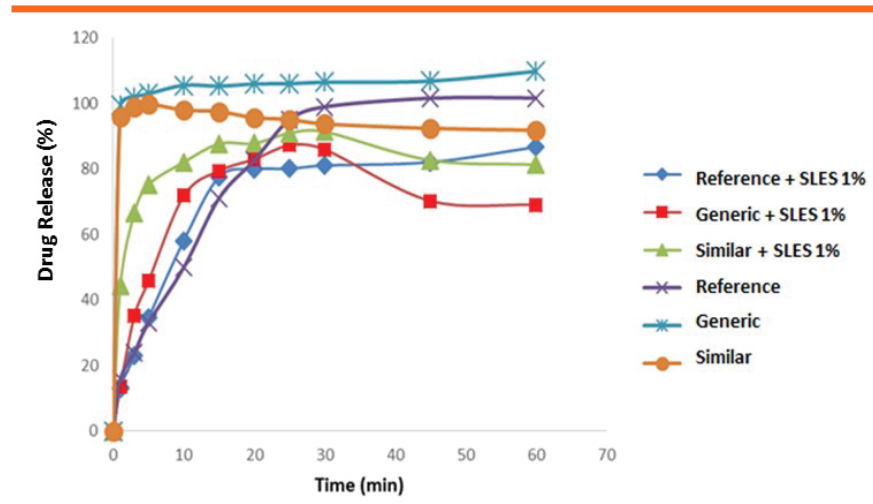

Figure 3. Comparative dissolution profiles of propranolol $(40 \mathrm{mg})$ tablets of reference, generic, and similar products with and without sodium lauryl ether sulfate (SLES) 1\% (v/v). (USP type 1 apparatus at $100 \mathrm{rpm}$ with $1000 \mathrm{~mL} 0.1 \mathrm{~mol} / \mathrm{L} \mathrm{HCl}$ at $37.0 \pm 0.5^{\circ} \mathrm{C}$ for $1 \mathrm{~h}$ ).

As a surfactant, SLES was expected to accelerate further dissolution of the drug; however, it slowed down the process by $20 \%-30 \%$, influencing the dissolution. Some hypotheses to explain the occurrence are 
proposed: 1) propranolol has a polar part, which may have undergone interaction with SLES, generating a complexation reaction (Fig. 4) and delaying the dissolution process, because the surfactant's action is reduced due to binding in polar substances; 2) SLES can undergo acid hydrolysis and the $\mathrm{pH}$ value of the final solution was 4.4, which may have reduced the action of the surfactant (30). SLES is an anionic emulsifier, which generates an electron-donating effect on the molecule. This portion of sulfate can interact with several molecules, to the point of influencing the release of propranolol, forming a complex with itself (38). As seen in Figure 4, the propranolol molecule has partially positive charge points on some carbons adjacent to an electron withdrawing group, such as oxygen, amine, and hydroxyl. Also, there is an effect on hydrogen bonding, since propranolol has portions with electronegative elements (nitrogen) that can undergo this type of binding. These hypotheses are based on the chemical groups present in propranolol and their reactional capacity.

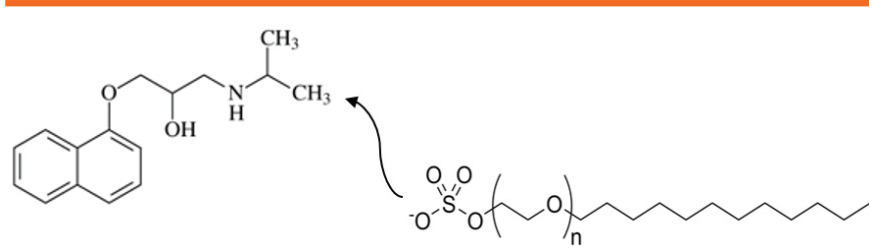

Figure 4. Hypothesis of interaction between Propranolol and sodium lauryl ether sulfate (SLES) $1 \%(\mathrm{v} / \mathrm{v})$.

The quality control carried out in pharmaceutical industries is controlled by regulatory agencies, which is extremely important to ensure the microbiological and physical-chemical quality of the materials and final products. Several factors related to the drug, the reaction medium, and the production can influence the kinetics of dissolution. The development of biopharmaceutical studies is essential for ensuring the quality control of solid oral dosage forms.

\section{CONCLUSION}

Propranolol tablets $(40 \mathrm{mg})$ were analyzed across general tests (weight variation and friability) and kinetic dissolution studies (disintegration and dissolution tests). A rapid and sensitive UV spectrophotometric method was developed with good linearity, precision, and accuracy. The products met the Brazilian and United States Pharmacopoeias recommendations for disintegration and dissolution tests. The dissolution profiles showed a rapid release of propranolol in generic and similar drug products. In the presence of SLES 1\% (v/v), propranolol release was slower. Drug release was satisfactory for all products: at least $75 \%$ of the propranolol was dissolved in the medium within $30 \mathrm{~min}$ of the test.

\section{ACKNOWLEDGEMENTS}

The authors are grateful for the financial support received from Bahia State Research Support Foundation (FAPESB) and Brazilian National Council for Scientific and Technological Development (CNPq). Research Group: "Biopharmaceutics and Drugs", State University of Bahia (UNEB).

\section{CONFLICT OF INTEREST}

The authors disclosed no conflicts of interest related to this article.

\section{REFERENCES}

1. Frishman, W. H. Beta-adrenergic receptor blockers in hypertension: alive and well. Prog. Cardiovasc. Dis. 2016, 59, 247-252. DOI: 10.1016/j.pcad.2016.10.005.

2. Westfall, T. C.; Westfall, D. P. Adrenergic agonists and antagonists. In: The Pharmacological Bases of Therapeutic, 12st ed.; Brunton, L. L.; Chabner, B. A.; Knollman, B. C., eds.; Porto Alegre: McGraw Hill; 2011, pp 277-333.

3. lacobellis, G.; Sharma, A. M. Epicardial adipose tissue as new cardiometabolic risk marker and potential therapeutic target in the metabolic syndrome. Curr. Pharm. Des. 2007, 13, 21802184. DOI: 10.2174/138161207781039670.

4. Mansur, A. P.; Avakian, S. D.; Paula, R. S.; Donzella, H.; Santos, S. R. C. J.; Ramires, J. A. F. Pharmacokinetics and pharmacodynamics of propranolol in hypertensive patients after sublingual administration: systemic availability. Braz. J. Med. Biol. Res. 1998, 31, 691-696. DOI: 10.1590/S0100-879X1998000500014.

5. Shand, D. G. Pharmacokinetics of propranolol: a review. Postgrad. Med. J. 1976, 52 (suppl. 4), 22-25.

6. Cheng, C.; Wu, P. C.; Lee, H. Y.; Hsu, K. Y. Development and validation of an in vitro-in vivo correlation (IVIVC) model for propranolol hydrochloride extended-release matrix formulations. J. Food Drug Anal. 2014, 22, 257-263. DOI: 10.1016/j.jfda.2013.09.016.

7. Eddington, N. D.; Ashraf, M.; Augsburger, L. L.; Leslie, J. L.; Fossler, M. J.; Lesko, L. J.; Shah, V. P.; Rekhi, G. S. Identification of formulation and manufacturing variables that influence in vitro dissolution and in vivo bioavailability of propranolol hydrochloride tablets. Pharm. Dev. Technol. 1998, 3, 535-547. DOI: 10.3109/10837459809028636.

8. National Relation of essential medicines (RENAME). Secretariat of Science, Technology and Strategic Inputs, Department of Pharmaceutical Assistance and Strategic Inputs. Ministry of Health: Brasilia, DF: 2017. Accessed Oct 5, 2017. http:// bvsms.saude.gov.br/bvs/publicacoes/relacao_nacional_ medicamentos_rename_2017.pdf. 
9. Concepts and definitions of medicines. Brazilian Health Surveillance Agency (ANVISA): Brasília, 2011. Accessed Nov 13, 2017. http://portal.anvisa.gov.br/medicamentos/conceitos-edefinicoes.

10. Ansel, H. C.; Popovich, N. G.; Allen, L. V. Pharmaceutical Forms and Drug Delivery Systems, 9th ed; Porto Alegre: Artmed; 2013, pp 35-45.

11. Amidon, G. L.; Lennernas H., Shah, V. P.; Crison, J. R. A theoretical basis for a biopharmaceutic drug classification: the correlation of in vitro drug product dissolution and in vivo bioavailability. Pharm. Res. 1995, 12,413-420. DOI: 10.1023/A:1016212804288.

12. Resolution of the Board of Directors - RDC No. 37. Ministry of Health, Brazilian Health Surveillance Agency (ANVISA): Brasilia, August 3, 2011. Accessed Oct 3, 2017. https://www20.anvisa. gov.br/coifa/pdf/rdc37.pdf.

13. Anand, O.; Yu, L. X.; Conner, D. P.; Davit, B. M. Dissolution testing for generic drugs: an FDA perspective. AAPS J. 2011, 13, 328335. DOI: 10.1208/s12248-011-9272-y.

14. Qureshi, S. A. Developing discriminatory drug dissolution tests and profiles: Some thoughts for consideration on the concept and its interpretation. Dissolution Technol. 2006, 13, 18-23. DOI: 10.14227/DT130406P18.

15. Menegola, J.; Steppe, M.; Schapoval, E. E. S. Dissolution test for citalopram in tablets and comparison of in vitro dissolution profiles. Eur. J. Pharm. Biopharm. 2007, 67, 524-530. DOI: 10.1016/j.ejpb.2007.02.009.

16. Rodrigues, P. O.; Stulzer, H. K.; Cruz, A. P.; Foppa, T.; Cardoso, T. M.; Silva, M. A. S. Pharmaceutical equivalence between propranolol tablets marketing in national market. Infarma 2006, 8, 3-7.

17. Hernawan, H.; Nurhayati, S.; Nisa, K.; Indrianingsih, A. W.; Darsih, C.; Kismurtono, M. Formulation and in vitro study of propranolol hydrochloride controlled release from carboxymethyl chitosanbased matrix tablets. Indo. J. Chem. 2013, 13, 242-247.

18. Rigobello, C.; Gasparetto, A. V.; Diniz, A.; Rabito, M. F.; Nery, M. M. F. Quality assessment and dissolution profile of propranolol hydrochloride tablets. Acta Sci. Health Sci. 2013, 35, 85-90. DOI: 10.4025/actascihealthsci.v35i1.12307.

19. Sahoo, J.; Murthy, P. N.; Biswal, S.; Sahoo, S. K.; Mahapatra, A. K. Comparative study of propranolol hydrochloride release from matrix tablets with KollidonSR or hydroxy propyl methyl cellulose. AAPS PharmSciTech 2008, 9, 577-582. DOI: 10.1208/ s12249-008-9092-2.

20. Bartolomei, M.; Bertocchi, P.; Ramusino, M. C.; Santucci, N.; Valvo, L. Physico-chemical characterisation of the modifications I and II of (R,S) propranolol hydrochloride: solubility and dissolution studies. J. Pharm. Biomed. Anal. 1999, 21, 299-209. DOI: 10.1016/S0731-7085(99)00128-4.

21. Horter, D.; Dressman, J. B. Influence of physicochemical properties on dissolution of drugs in the gastrointestinal tract. Adv. Drug Deliv Rev. 2001, 46, 75-87. DOI: 10.1016/S0169409x(00)00130-7.
22. Brazilian Pharmacopeia, 5th ed.; Brasilia: Brazilian Health Surveillance Agency; 2010.

23. The United States Pharmacopeia and National Formulary USP 34-NF 29; The United States Pharmacopeial Convention, Inc.: Rockville, MD, 2011.

24. Khan, K. A. The concept of dissolution efficiency. J. Pharm. Pharmacol. 1975, 27, 48-49. DOI: 10.1111/j.2042-7158.1975. tb09378.x.

25. Resolution of the Board of Directors - RDC No. 899. Ministry of Health, Brazilian Health Surveillance Agency (ANVISA): Brasília, May 29, 2003. Accessed Oct 3, 2017. http://portal.anvisa.gov. br/documents/10181/2718376/RE_899_2003_COMP.pdf/ ff6fdc6b-3ad1-4d0f-9af2-3625422e6f4b.

26. Resolution - RDC No. 31. Ministry of Health, Brazilian Health Surveillance Agency (ANVISA): Brasilia, August 11, 2010. Accessed Oct 5, 2017. http://portal.anvisa.gov. br/documents/33880/2568070/res0031_11_08_2010. pdf/5e157d15-d3d5-4bb9-98db-5667e4d9e0c8.

27. International Conference on Harmonisation (ICH) of Technical Requirements for Registration of Pharmaceuticals for Human Use. Validation of Analytical Procedures: Text and Methodology Q2(R1); ICH Harmonised Tripartite Guideline: Geneva, Switzerland, 2005. Accessed Oct 2, 2017. https://www.ich.org/ fileadmin/Public_Web_Site/ICH_Products/Guidelines/Quality/ Q2_R1/Step4/Q2_R1_Guideline.pdf.

28. Ferreira, M. S.; Viana, L. C. M. G.; Matos, R. A.; Sá, R. R.; Silva, F. A. S.; Mota, M. D.; Cazedey, E. C. L.; Magalhães, H. I. F.; Santos, A. F. Jr. Comparative in vitro analysis of dissolution profiles of furosemide tablets marketed in Bahia, Brazil. Lat. Am. J. Pharm. 2016, 35, 2064-2070.

29. Storpirtis, S.; Gonçalves, J. E.; Chiann, C.; Gai, M. N. Biopharmacotechnics. Rio de Janeiro: Guanabara Koogan; 2011, pp 35.

30. Rowe, R. C.; Sheskey, P. J.; Quinn, M. E. Handbook of Pharmaceutical Excipientes, 6rd ed.; Farmaceutical Press: London, 2009, 352-360.

31. Gil, E. S.; Brandão, A. L. A. Excipients: Its Applications and Physical-Chemical Control, 2nd ed.; São Paulo: Pharmabooks; 2007, 110-125.

32. Rumel, D.; Nishioka, S. A.; Santos, A. A. M. Drug interchangeability:clinical approach and consumer's point of view. Rev. Saúde Pública. 2006, 40, 1-7. DOI: 10.1590/S003489102006000600024.

33. Kesselheim, A. S.; Misono, A. S.; Lee, J. L.; Stedman, M. R.; Brookhart, A.; Choudhry, N. K.; Shrank, W. H. Clinical equivalence of generic and brand-name drugs used in cardiovascular disease: a systematic review and meta-analysis. JAMA 2008, 300, 25142526. DOI: 10.1001/jama.2008.758.

34. Villanova, J. C. O.; Sá, V. R. Excipients: Practical Guide to Standardization; São Paulo: Pharmabooks, 2009, 109-110. 
35. Olkowska E.; Polkowska Z.; Namieśnik J. Analytics of surfactants in the environment: problems and challenges. Chem. Rev. 2011, 111, 5667-5700. DOI: 10.1021/cr100107g.

36. Silva, R. L.; Volpato, N. M. Means for the Dissolution of Nimesulide Tablets: action of Surfactants. Braz. J. Pharm. Sci. 2002, 38, 163-172. DOI: 10.1590/S1516-93322002000200005.
37. Storey, D. E. The role of dissolution testing in the dosing of immediate release dosage forms. Drug Inf. J. 1996, 30, 10391044. DOI: 10.1177/009286159603000420.

38. Lu, H.; Drelich, A.; Omri, M.; Pezron, I.; Wadouachi, A.; Pourceau, G. Catalytic synthesis of a new series of alkyl uronates and evaluation of their physicochemical properties. Molecules 2016, 21, 1301-1315. DOI: 10.3390/molecules21101301.

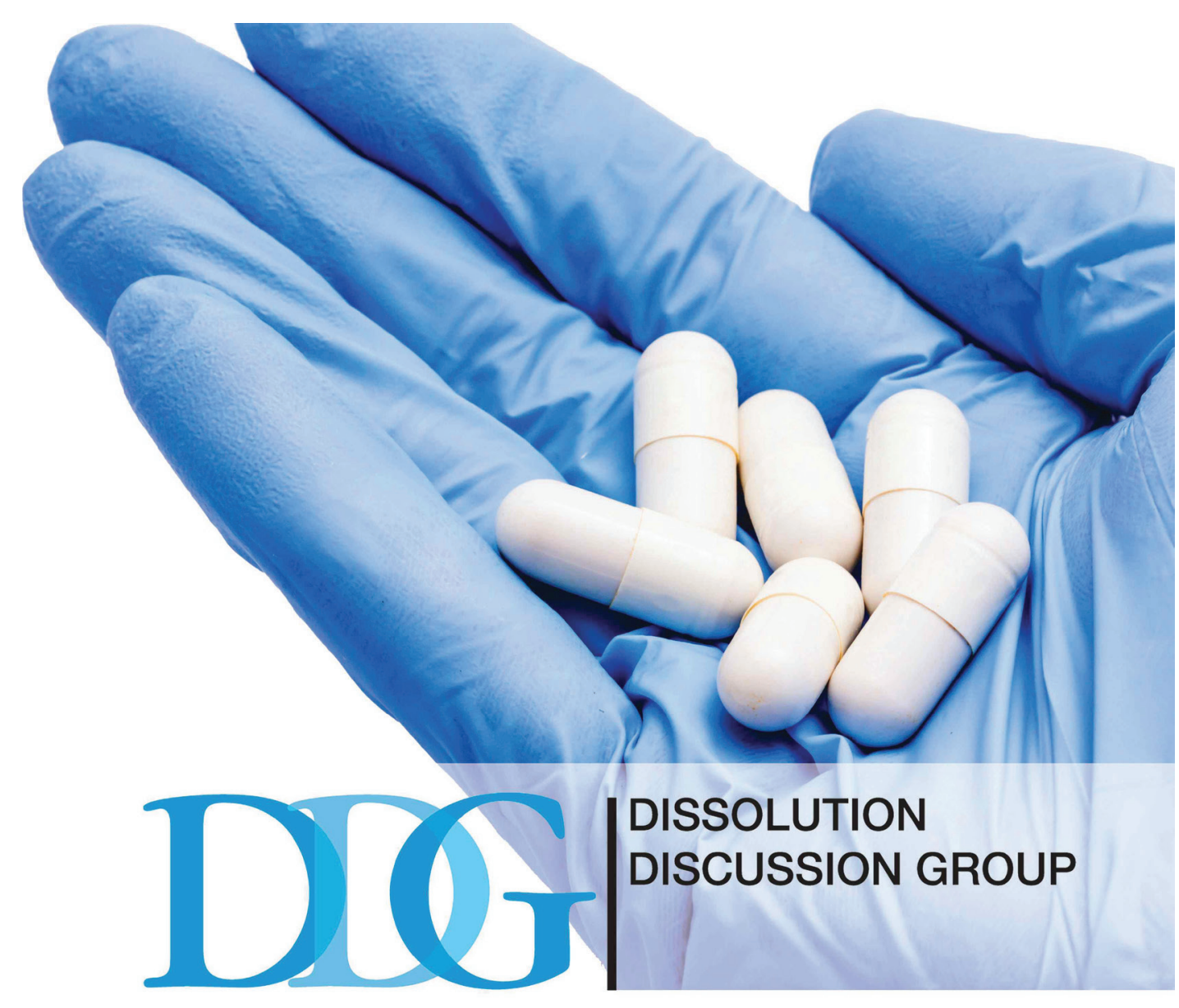

For 20 years, the DDG has advanced the science of dissolution through the sharing of expertise

\section{Thousands of questions and answers are at your fingertips in our online forum}

\section{Participate in quarterly online meetings or peruse our extensive archive of recorded meetings}

www.dissolution.com 